\title{
Utility and Yield of Genetic Testing Leading to a Definitive Neuromuscular or Neuropathic Diagnosis at a Rural Outpatient Neurology Clinic Affiliated with a University Health Center in West Virginia over 4 Years
}

Holly Farkosh, MS4', Dominika Lozowska, MD²

\section{ABSTRACT}

BACKGROUND: Clinicians are increasingly relying on genetic testing to pinpoint definite diagnoses. A more general diagnosis of neuropathy or neuromuscular disease like myopathy can be narrowed down substantially using genetic testing. Because carrier status is of utmost importance in reproductive matters, pathogenic results can prognosticate the future course of the illness and help plan ahead for treatment and social supports. Given the expense of genetic testing, it is important to assess the cost-benefit ratio to determine whether it is worthwhile to collect genetic samples. The purpose of the study was to determine the likelihood of obtaining a conclusive confirmatory diagnosis through genetic testing (measured as the percent of positive results obtained out of all the submitted samples).

METHODS: A single clinician's record of genetic test outcomes was reviewed spanning four years from July 2015 to June 2019 to identify those who had submitted genetic samples to Invitae, a commercial lab in California that offers affordable genetic testing. All patients were evaluated for complaints of neuromuscular and neuropathic nature using the standard of care workup that included a physical exam, lab tests, nerve conduction study (NCS), electromyography (EMG), and/or muscle biopsy before sending out for genetic testing. The positive, negative, and indeterminate genetic diagnoses were tabulated, and the individual disease entities' prevalence was determined.

Results: Of the patients who participated in genetic testing, 96 were diagnosed with neuropathic conditions and 59 with neuromuscular conditions. The patients' health records did not have to be mined for results because the clinician's Invitae account contained de-identified requisition numbers linked to their results. The patients in the neuromuscular group had twice as many positive results as those in the neuropathic group. There were about three times as many normal results in the neuropathic group compared to the neuromuscular group. Around half of all test samples showed indeterminate results containing variants of unknown significance (VOUS), which were not indicative of any pathology and were considered inconclusive.

ConcLusion: Based on the study findings, there were $17.7 \%$ and $35.6 \%$ positive (meaning pathogenic) results, respectively, among neuropathic and neuromuscular cases sent off for genetic analysis. While 38 out of 155 total cases makes up a small, $24.5 \%$ yield of abnormal results, genetic studies are still a worthwhile addition to investigating neuropathic and neuromuscular cases.

\section{KEYWORDS}

Genetic Testing, Neurology, Rural, West Virginia
Author affiliations are listed at the end of this article.

Correspondence to: Holly Farkosh, MS4 Marshall Unviersity Joan C. Edwards School of Medicine farkosh@live.marshall.edu 


\section{INTRODUCTION}

Genetic testing has come to the forefront as one of the tools a neurologist uses more frequently than ever as the next step for patient care after a detailed history, careful exam, and appropriate workup, including labs and EMG/NCS studies. It may even eliminate the need for a muscle, skin, or nerve biopsy, depending on the particular situation and the clinician's judgment. This article is a retrospective review of all genetic results for nextgeneration, sequencing-based gene panel testing of patient samples obtained at a neurology clinic by one provider to determine the percentage of success in reaching a definitive diagnosis (i.e., a particular type of neuropathy or myopathy) and thus prognosticating future disease course and implications for relatives if any.

\section{METHODS}

This study was approved by the Marshall University Institutional Review Board (IRB), protocol number 1427509. The research design consisted of a retrospective record review of de-identified genetic

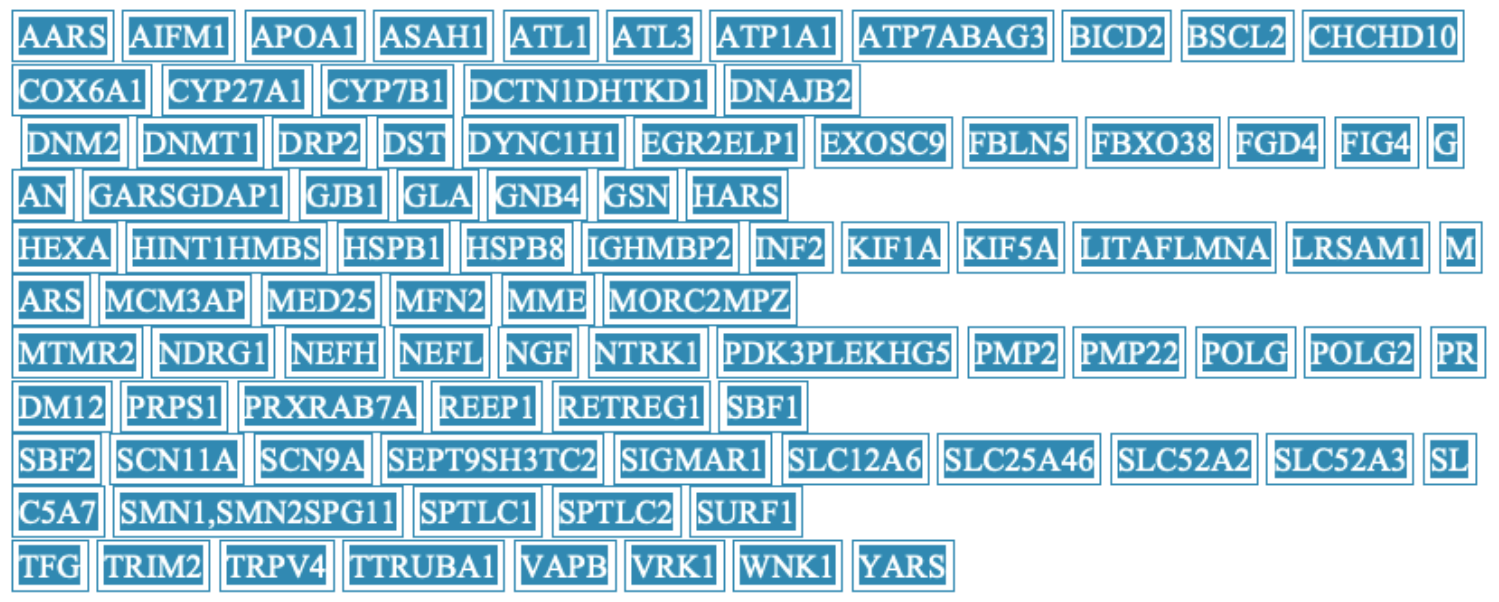

FIGURE 1. The 102 genes tested for in the Invitae comprehensive neuropathy disorders panel.

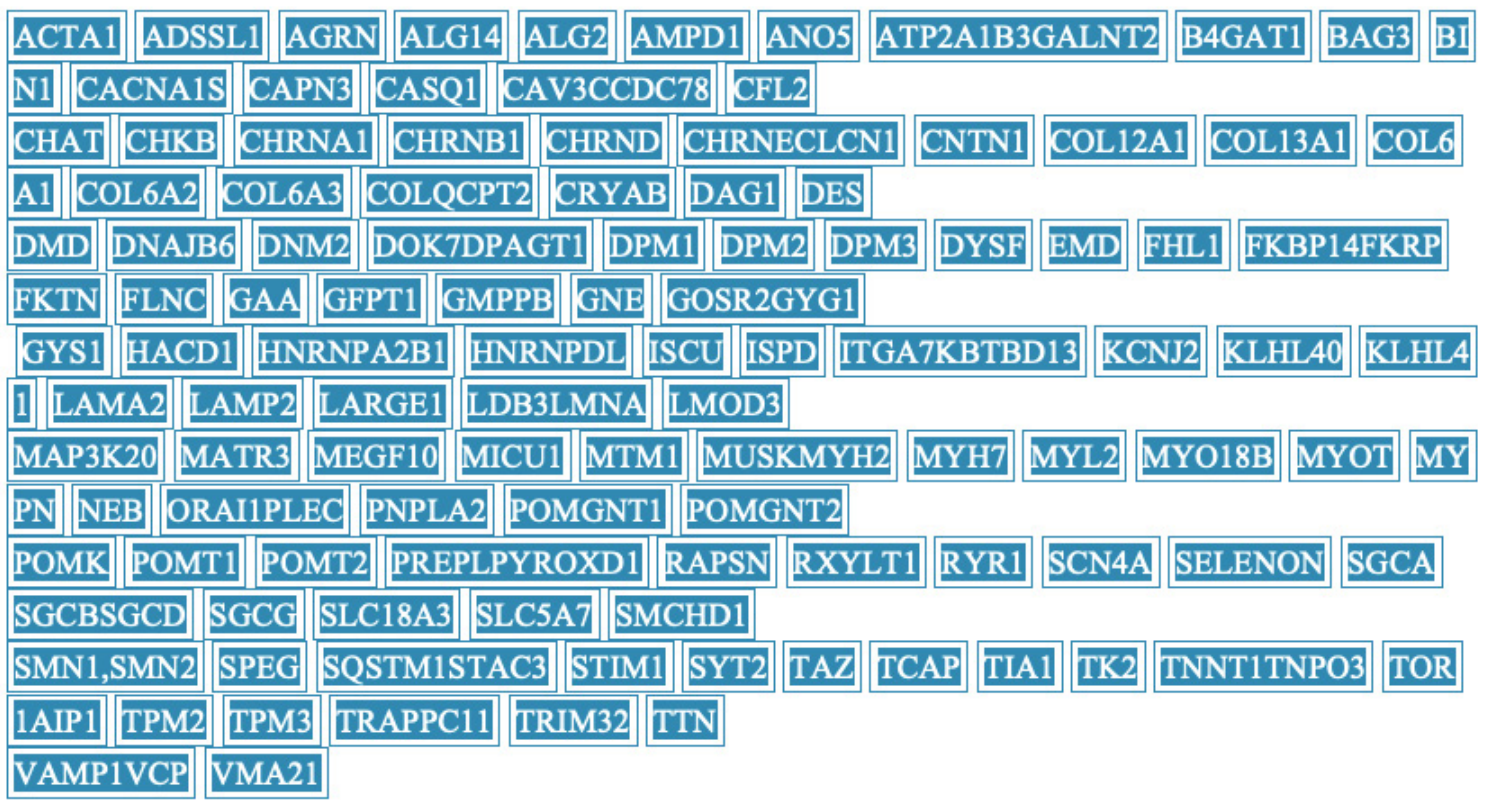

FIGURE 2. The 103 genes tested for in the Invitae comprehensive neuromuscular disorders panel. 
results for neurology patients who presented to a single practitioner's outpatient clinic with complaints suggestive of a neuromuscular problem such as weakness, atrophy, or myalgias, versus a neuropathic problem such as numbness, paresthesias, or falls. Patients already had a suitable workup and gave their consent to submit a genetic sample to gather more definitive information about their condition and its inheritance pattern or to confirm the clinical diagnosis. The Invitae neuropathy panel contained 102 genes (figure 1), and the neuromuscular panel contained 131 genes (figure 2). Inclusion criteria were to include those who presented with neuropathic and neuromuscular

\section{Genetic results of 96 samples analyzed by the Invitae neuropathy panel}

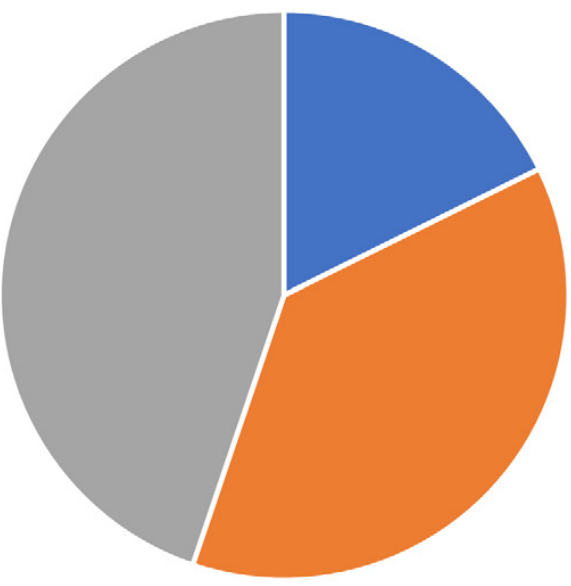

nositive $17.7 \%$

- negative $37.5 \%$ indeterminate $44.8 \%$

FIGURE 3. Pie chart of Invitae neuropathy panel results.

\section{Genetic results of 59 samples analyzed by the Invitae neuromuscular panel}

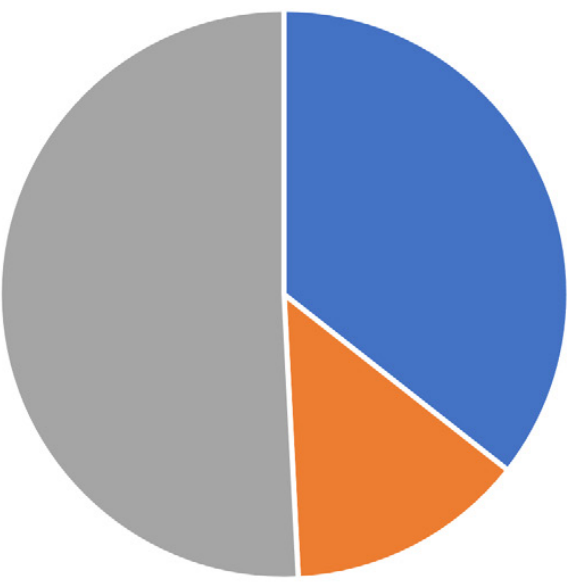

- positive $35.6 \%$ - negative $13.6 \%$ | indeterminate $50.8 \%$

FIGURE 4. Pie chart of Invitae neuromuscular panel results. 
complaints and who were studied with Invitae's neuropathic or neuromuscular comprehensive gene panel. Exclusion criteria were to exclude patients who were genetically tested for other conditions due to symptoms concerning Parkinson's, Alzheimer's, and neurofibromatosis. Referrals came from tertiary or private offices in the local tri-state area (West Virginia, Kentucky, and Ohio), the VA hospital, and colleagues in practice. Neurophysiology using NCS/EMG studies was employed in the majority of cases to distinguish myopathic from neuropathic conditions and to grade the severity. Data entry consisted of arranging anonymous findings consisting of 6 digit requisition numbers in an excel spreadsheet and then tabulating the mutation(s) involved, carrier status, pathogenicity, or lack thereof,

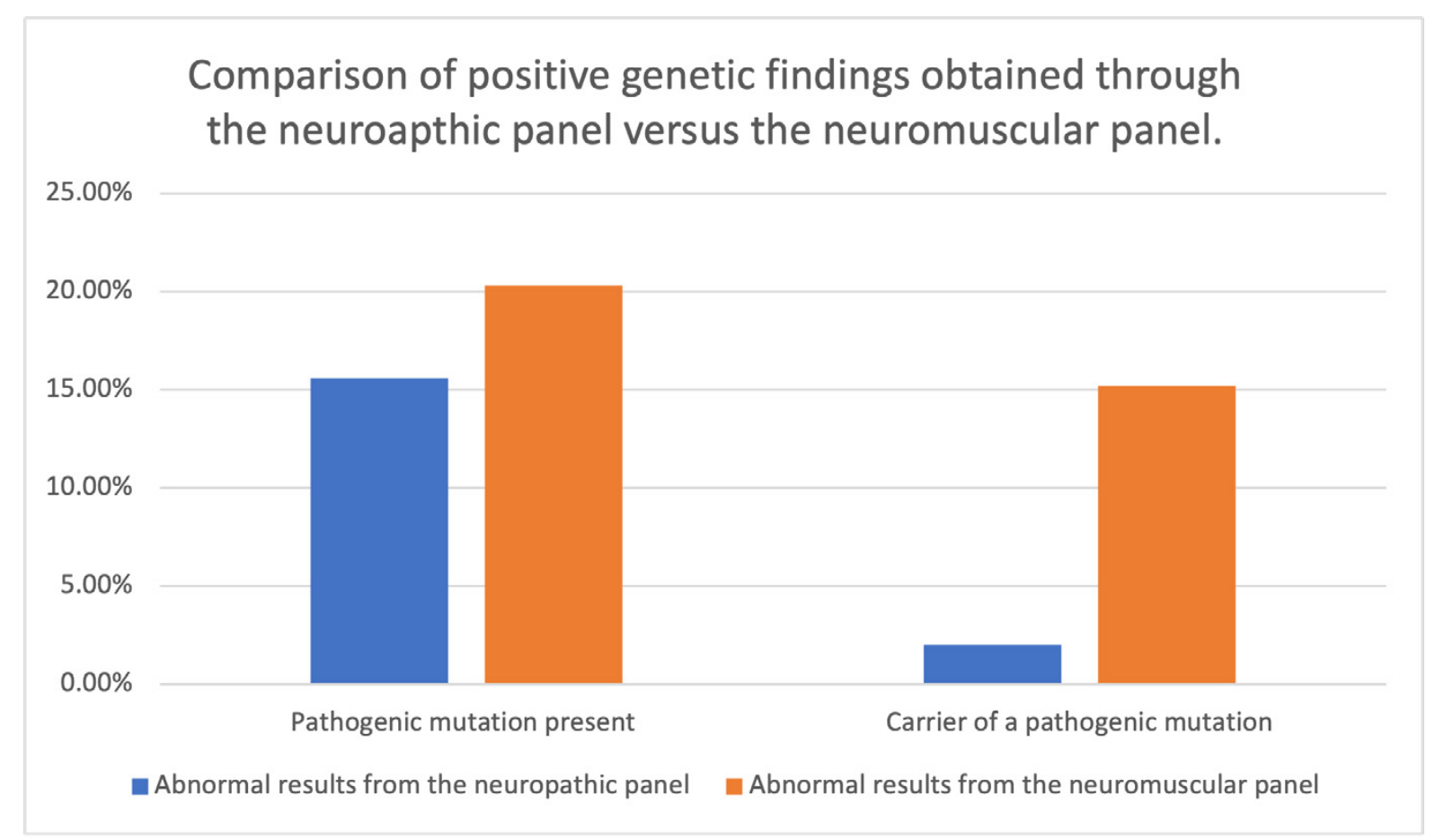

FIGURE 5. Comparison of abnormal genetic results.

\begin{tabular}{|c|c|c|c|c|c|c|}
\hline $\begin{array}{l}\text { Pathogenic } \\
\text { mutations }\end{array}$ & $\begin{array}{l}\text { Five } \\
\text { PMP22 } \\
\text { mutations } \\
\text { (AD } \\
\text { Charcot } \\
\text { Marie } \\
\text { Tooth } \\
\text { type 1a) }\end{array}$ & $\begin{array}{l}\text { Four GJB1 } \\
\text { mutations } \\
\text { (X-linked } \\
\text { Charcot } \\
\text { Marie } \\
\text { Tooth type } \\
\text { 1x) }\end{array}$ & $\begin{array}{l}\text { Three } \\
\text { MFN2 } \\
\text { mutations } \\
\text { (AD } \\
\text { Charcot } \\
\text { Marie } \\
\text { Tooth } \\
\text { type 1a) }\end{array}$ & $\begin{array}{l}\text { One } \\
\text { MPZ } \\
\text { mutation } \\
\text { (AD } \\
\text { Charcot } \\
\text { Marie } \\
\text { Tooth } \\
\text { type 1b) }\end{array}$ & $\begin{array}{l}\text { One } \\
\text { SPTLC2 } \\
\text { mutation } \\
\text { (AD } \\
\text { Hereditary } \\
\text { Sensory } \\
\text { Autonomic } \\
\text { Neuropathy } \\
\text { type 1c) }\end{array}$ & $\begin{array}{l}\text { One } \\
\text { LITAF } \\
\text { mutation } \\
\text { (AD } \\
\text { Charcot } \\
\text { Marie } \\
\text { Tooth } \\
\text { type 1c) }\end{array}$ \\
\hline $\begin{array}{l}\text { Carriers } \\
\text { of } \\
\text { Pathogenic } \\
\text { mutation }\end{array}$ & $\begin{array}{l}\text { One FIG4 } \\
\text { (AR } \\
\text { Charcot } \\
\text { Marie } \\
\text { Tooth } \\
\text { type 4) }\end{array}$ & $\begin{array}{l}\text { One } \\
\text { PLEKGH2 } \\
\text { (AR } \\
\text { Charcot } \\
\text { Marie } \\
\text { Tooth type } \\
\text { C) }\end{array}$ & & & & \\
\hline
\end{tabular}

FIGURE 6. Listing of the number of the particular gene mutations found via the Invitae neuropathic panel and the associated disease conditions caused by them. AD (autosomal dominant), AR (autosomal recessive). 


\begin{tabular}{|c|c|c|c|c|c|c|c|}
\hline $\begin{array}{l}\text { Pathogenic } \\
\text { mutations }\end{array}$ & $\begin{array}{l}\text { Three } \\
\text { COL6A3 } \\
\text { mutations } \\
\text { (AD Bethlem } \\
\text { myopathy) }\end{array}$ & $\begin{array}{l}\text { Three SCN4 } \\
\text { mutations } \\
\text { (AD } \\
\text { paramyotonia } \\
\text { congenita) }\end{array}$ & $\begin{array}{l}\text { Two } \\
\text { MYH7 } \\
\text { mutations } \\
\text { (AD Laing } \\
\text { distal } \\
\text { myopathy) }\end{array}$ & $\begin{array}{l}\text { Two } \\
\text { CLCN1 } \\
\text { mutations } \\
\text { (AD } \\
\text { myotonia } \\
\text { congenita) }\end{array}$ & $\begin{array}{l}\text { One } \\
\text { SMN2 } \\
\text { mutation } \\
\text { (AR } \\
\text { spinal } \\
\text { muscular } \\
\text { atrophy) }\end{array}$ & $\begin{array}{l}\text { One DNM2 } \\
\text { mutation } \\
\text { (AD } \\
\text { centronuclear } \\
\text { myopathy) }\end{array}$ & \\
\hline $\begin{array}{l}\text { Carrier of } \\
\text { pathogenic } \\
\text { mutations }\end{array}$ & $\begin{array}{l}\text { Three NEB } \\
\text { mutations } \\
\text { (AR } \\
\text { nemaline } \\
\text { myopathy) }\end{array}$ & $\begin{array}{l}\text { One CLCN1 } \\
\text { mutation } \\
\text { (AR myotonia } \\
\text { congenita) }\end{array}$ & $\begin{array}{l}\text { One SMN1 } \\
\text { mutation } \\
\text { (AR spinal } \\
\text { muscular } \\
\text { atrophy) } \\
\text { with } \\
\text { SPG11 } \\
\text { mutation } \\
\text { (AR } \\
\text { hereditary } \\
\text { spastic } \\
\text { paraplegia } \\
\text { 11) } \\
\end{array}$ & $\begin{array}{l}\text { One } \\
\text { SMN1 } \\
\text { mutation } \\
\text { (AR } \\
\text { spinal } \\
\text { muscular } \\
\text { atrophy) }\end{array}$ & $\begin{array}{l}\text { One } \\
\text { TRIM2 } \\
\text { mutation } \\
\text { (AR limb } \\
\text { girdle } \\
\text { muscular } \\
\text { dystrophy } \\
\text { 2H) }\end{array}$ & $\begin{array}{l}\text { One GMPPB } \\
\text { mutation } \\
\text { (AR } \\
\text { muscular } \\
\text { dystrophy- } \\
\text { dystroglycono } \\
\text { pathy C14) }\end{array}$ & $\begin{array}{l}\text { One } \\
\text { CHRNB } \\
\text { mutation } \\
\text { (AR } \\
\text { congenital } \\
\text { myasthenic } \\
\text { syndrome) }\end{array}$ \\
\hline
\end{tabular}

FIGURE 7. Listing of the number of the particular gene mutations found via the Invitae neuromuscular panel and the associated disease conditions caused by them. AD (autosomal dominant), AR (autosomal recessive).

along with the presence of inconclusive variants of unknown significance (VOUS).

\section{RESULTS}

One hundred and fifty-five cases were identified as eligible for inclusion in the study. Of these, $96 \mathrm{had}$ been diagnosed with neuropathy and underwent genetic testing with the Invitae comprehensive neuropathy disorders panel, and 59 had been diagnosed with a neuromuscular condition, such as a probable myopathy, and underwent genetic testing with the Invitae comprehensive neuromuscular disorders panel. Out of 96 neuropathic cases, 17 had abnormal, 36 had normal, and 43 had indeterminate results. Of the 17 abnormal neuropathic cases, 15 had an autosomal dominant or X-linked pathogenic mutation pattern, and two were carriers of an autosomal recessive (AR) pathogenic mutation. Out of 59 neuromuscular cases, 21 had abnormal, 8 had normal, and 30 had indeterminate results. Of the 21 abnormal neuromuscular cases, 12 had an autosomal dominant pathogenic mutation pattern, and 9 were carriers of an autosomal recessive (AR) pathogenic mutation. The major disease categories identified are described in figure 6 and figure 7. There were twice as many positive results in the neuromuscular group $(35.6 \%)$ as in the neuropathic group (17.7\%). There were about three times as many normal results in the neuropathic group (37.5\%) as in the neuromuscular group (13.6\%). The yield of variants of unknown significance (VOUS) was roughly half of all the tests sent: $44.8 \%$ in the neuropathic group and $50.8 \%$ in the neuromuscular group.

\section{DISCUSSION}

The literature does not contain a lot of specific data about the prevalence of neuropathic and neuromuscular disease in West Virginia. In 1987, Benson et al. mentioned an Appalachian region kindred with familial amyloid polyneuropathy. ${ }^{1}$ West Virginians may be somewhat under-represented in the field of genetic research for various reasons such as poverty level, lack of access to higher education centers and resources due to financial and transportation difficulties, etc., but when looking at cancer as a leading cause of death in Appalachia, Llanos et al. studied "predictors of willingness to participate in biospecimen donation and biobanking among Appalachian adults" and found that 97\% of those who agreed to be tested were willing to have their samples sent for genetic studies. ${ }^{2}$ We aimed to expand knowledge about which genetic conditions might be uncovered at a single clinician's neurology practice in 4 years at a rural outpatient 
neurology clinic in WV. We had 155 patients who expressed interest in genetic testing, excluding those who agreed to be tested for symptoms other than neuropathic or neuromuscular. One limitation of our study is that the number of cases sent for genetic testing is dependent on the clinical acumen of the clinician and the workup leading up to the decision to extend genetic testing to patients. While it was not feasible to obtain second opinions on all 155 patient cases, if we did, it might have been useful to only send those cases for genetic testing, where the other clinician saw a need for it too. Another limitation is the small sample size, which may not be representative of other regions of WV. We could have, perhaps, captured a larger number of cases if we invited other neurology practices to participate in our study, perhaps even the other universitybased practice in WV that also frequently performs genetic testing. The study drew cases from only one clinician's practice, so the case numbers are low due to the clinician seeing other general neurology cases besides patients voicing neuropathic and neuromuscular problems. In a more large-scale population study in Northern England, where prevalence was calculated per 100,000 inhabitants, they were able to confirm the presence of a condition by genetic testing in $75.7 \%$ of those whom they studied. ${ }^{3}$

Usually, the diagnostic algorithm in a neurology clinic involves asking about developmental history, specifically, the presence of contractures at birth, developmental milestones, ability to keep up with peers in races, a pattern of wearing out shoe soles, cramps, paresthesias, and any inheritance pattern among relatives with similar symptoms. The exam may reveal pes cavus, thin calves, sensory loss, foot drop, proximal weakness, or scapular winging. After sending a combination of labs that may include but aren't limited to A1C, CPK, B12, and serum electrophoresis, an NCS/EMG study becomes instrumental in pinpointing a need for further testing. Genetic testing with next-generation sequencing (NGS) may help uncover an explanation for a multisystem disease process of neuropathic or myopathic disease and help to pinpoint a specific neuropathy subtype, of which there are many. While whole-exome sequencing is being clinically used, it is more costly, has a higher false-positive rate, a longer turnaround time, and is more difficult to interpret compared to targeted NGS. ${ }^{4}$ Our study notably confirmed that among the cases suspected of having a neuropathic condition, as shown in figure 6 , there were 14 cases of different CMT subtypes, 2 carriers of different CMT subtypes, and 1 of Hereditary Sensory Autonomic Neuropathy type 1c. Among CMT sufferers, the most common was a PMP22 mutation ( 5 cases), then GJB1 mutation (4 cases), then MFN2 mutation (3 cases). There was 1 case each of MPZ, SPTLC2, and LITAF mutation causing CMT. CMT is quite prevalent in the general population ( 1 in 25,000 ), so that was not unexpected. ${ }^{5}$

In terms of neuromuscular disease, as shown in figure 7, our study predominantly confirmed 3 cases of paramyotonia congenita, 3 cases of Bethlem myopathy, 2 cases of myotonia congenita, 2 cases of Laing distal myopathy, 1 case of centronuclear myopathy, and 1 case of spinal muscular atrophy. There were three carriers of nemaline myopathy and 6 carriers of other conditions (limb-girdle muscular dystrophy $2 \mathrm{H}$, congenital myasthenic syndrome, SMA, myotonia congenita, and muscular dystrophy-dystroglycanopathy (14). Curiously, 1 patient was a carrier of 2 disease conditions (SMA and hereditary spastic paraparesis). This shows that sometimes, sending a panel containing multiple genes is convenient because it can identify several mutations at once. However, casting a wide net for testing (including genetic testing) is still considered controversial, given that Greenberg et al stated the viewpoint that "testing should be performed as targeted studies, sometimes sequentially, but not as wasteful panels of multiple genetic tests performed simultaneously." ${ }^{\prime \prime}$ It appears that the clinician in our study sent off more test kits for neuropathy compared to the number of kits sent for neuromuscular testing but received fewer confirmations of genetically proven neuropathy, which indicates a potential tendency to overtest patients with a neuropathy presentation. This discrepancy could be due to the fact that neuropathies have many other potential etiologies besides being inherited, such as being caused by vitamin deficiencies, systemic illness (diabetes and hepatitis $\mathrm{C}$ ), or by medications (colchicine, amiodarone, or certain chemotherapeutics). The ease of sending a genetic panel may lead to over-reliance on it. 
Genetic testing is important because it can be informative about comorbidities that otherwise may not be immediately apparent. For example, the phenotype of high arches and hammertoes may hint at the presence of CMT. While a diagnosis may be made clinically, certain CMT subtypes like CMT type 6 coincide with ocular conditions that may be missed, were it not for genetic testing, and optic atrophy can be discovered earlier and sufficiently monitored. In the case of a patient who is misdiagnosed as CIDP based only on soft symptoms and prior NCS studies and is refractory to steroids or immunosuppressive treatment, genetic testing could potentially help reclassify him as CMT 1a. Sometimes, when looking for another suspected mutation, a discovery is made of a completely different sort, as in our study, where one ALS patient was found to be a carrier of AR spinal muscular atrophy. Another patient was found to be a carrier of 2 AR mutations: spinal muscular atrophy and hereditary spastic paraplegia 11. Normally, familial testing would be offered, but the ALS patient was adopted, and the other patient's relative wasn't interested in getting tested because she was unaffected.

One drawback of large panel genetic testing is the number of variants of unknown significance (VOUS) reported. VOUS are somewhat difficult to explain to the patient because they represent polymorphisms of uncertain significance. Those with indeterminate results may get reclassified in the future, as Invitae scans Exome Aggregation Consortium (ExAC) databases for other cases of VOUS reported. It is easier nowadays than previously to send a genetic test, especially on saliva, which can be collected in the office. The genetic test allows for arrival at a precise diagnosis which otherwise may not be established with confidence. A condition like muscular dystrophy or inherited neuropathy can be narrowed down with genetic testing to a subtype or even precisely characterized sooner than could be done by clinical exam or biopsy alone. There is often not enough time in the clinic to do a full pedigree or to examine close relatives in the office. A phone consultation via telemedicine with a geneticist may prove helpful when the lack of a geneticist on site prevents patients from attending genetic consultations for post-diagnosis counseling or arranging familial testing.
In terms of clinical application of genetic testing, let's take the example of a hypothetical Duchenne muscular dystrophy case. If the clinician has a high degree of suspicion upon seeing a young male patient with enlarged calves, who is walking on tiptoes and has elevated creatinine phosphokinase enzyme, a quick genetic test for large deletion/ duplication in the DMD gene or genetic sequencing for smaller point mutations can be obtained to arrive at the answer faster, rather than waiting to do a rather invasive EMG test or a muscle biopsy to check if dystrophin protein is absent in the patient's muscle fibers. The earlier the patient is diagnosed, the earlier he will have access to supportive care, orthotics, assistive devices, and treatments like steroids that help preserve respiratory function and delay ambulatory decline. His female relatives can also be tested to see if they are symptomatic carriers, which screens them for heart problems and weakness they may develop and gives them access to echocardiograms and specialist care, which they might not otherwise get. The personal impact of genetic testing on someone who, for example, has early motor neuron disease but very few symptoms and is still functioning may provide early genetic confirmation of the condition before progressive terminal illness ensues. This would allow some time for the patient to visit distant relatives or undertake travel before he becomes too ill to travel or would allow time for him to move to a better-adapted house that may be easier to access and navigate. In a case of spinal muscular atrophy (SMA), prior knowledge of having an inheritable mutation in the family pedigree may facilitate discussion of considerations for choosing alternative fertility options such as surrogacy or adoption to avoid passing on a condition that may have terminal or severe consequences to the next generation. Overall, genetic testing is highly conducive to streamlining and facilitating targeted care and treatment for patients.

\section{CONCLUSION}

The accumulated results showed the breadth of neuromuscular and neuropathic genetic conditions present in a typical patient population of a university outpatient neurology clinic in rural West Virginia (WV) over the course of 4 years during a single 
clinician's usual neurology workup supplemented by the extra step of genetic testing. Genetic testing of this population led to the identification of various heritable diseases such as CMT, paramyotonia congenita, Bethlem myopathy, congenital myotonia, and other rare conditions, the knowledge of which benefited the patients and their families.

\section{AUTHOR AFFILIATIONS}

1. Marshall University Joan C. Edwards School of Medicine, Huntington, West Virginia

2. Mon Health Medical Center, Department of Neurology, Morgantown, West Virginia

\section{REFERENCES}

1. Benson MD, Wallace MR, Tejada E, Baumann $\mathrm{H}$, Page B. Hereditary amyloidosis: description of a new american kindred with late onset cardiomyopathy. Vol. 30, Arthritis \& Rheumatism. 1987. p. 195-200.

2. Llanos $A A M$, Young GS, Baltic R, Lengerich EJ, Aumiller BB, Dignan MB, et al. Predictors of willingness to participate in biospecimen donation and biobanking among appalachian adults. J Health Care Poor Underserved. 2018;29(2):743-66.

3. Norwood FLM, Harling C, Chinnery PF, Eagle M, Bushby K, Straub V. Prevalence of genetic muscle disease in Northern England: In-depth analysis of a muscle clinic population. Brain. 2009;132(11):3175-86.

4. Chae JH, Vasta V, Cho A, Lim BC, Zhang Q, Eun $\mathrm{SH}$, et al. Utility of next generation sequencing in genetic diagnosis of early onset neuromuscular disorders. J Med Genet. 2015;52(3):208-16.

5. Cortese A, Wilcox JE, Polke JM, Poh R, Skorupinska M, Rossor AM, et al. Targeted nextgeneration sequencing panels in the diagnosis of Charcot-Marie-Tooth disease. Vol. 94, Neurology. 2020. p. e51-61.

6. Greenberg SA, Walsh RJ. Molecular diagnosis of inheritable neuromuscular disorders. Part II: Application of genetic testing in neuromuscular disease. Muscle Nerve [Internet]. 2005 Apr;31(4):431-451. Available from: https://doi. org/10.1002/mus.20279 